Rev. Elev. Méd. vét. Pays trop., 1975, 28 (2) : 235-237

\title{
Note sur l'insémination artificielle des zébus à Madagascar après synchronisation de l'œstrus par la norethandrolone $\left(^{*}\right)$
}

\author{
par H. SERRES et P. DUBO-S
}

\begin{abstract}
RESUME
Les auteurs rapportent trois essais d'insémination artificielle des femelles zébu après synchronisation de l'oestrus. De bons résultats sont obtenus avec la Noréthandrolone (environ 60 p. 100 de naissances).
\end{abstract}

L'amélioration génétique par croisements des zébus de Madagascar passait, jusqu'à ces derniers temps, par l'importation de géniteurs provenant de l'étranger. Cette pratique présentait de nombreux inconvénients liés aux problèmes sanitaires, à l'inadaptation du bétail importé, au coût de l'opération.

L'importation, par avion, de sperme congelé a ouvert une autre voie que nous avons explorée en pratiquant des inséminations artificielles.

Les premières inséminations ont été faites sur des vaches zébu dont les chaleurs étaient indiquées par les bouviers. Mais l'on sait combien les manifestations de l'œestrus sont discrètes chez ces animaux. Les erreurs ont été fréquentes et les résultats très mauvais.

L'année suivante, la détection de l'cestrus a été confiée à des taureaux vasectomisés. $\mathrm{La}$ méthode s'est montrée plus efficace, mais encore insuffisante.

C'est pourquoi nous avons adopté l'insémination artificielle après synchronisation de l'œstrus d'un groupe de femelles selon la technique mise au point à l'I.N.R.A. par MAU-

(") Nilevar N.D.
LEON, CHUPIN (*) et collab. $(2,3,4)$ et utilisant le Nilevar (1).

\section{LES ANIMAUX A INSEMINER}

Les femelles inséminées étaient des métis zebu malgache $\times$ zébu sahiwal, nées et élevées au Centre de Miadana en élevage extensif sur pâturages naturels. L'insémination a été pratiquée sur des génisses de 3 ans pesant entre 250 et $300 \mathrm{~kg}$ et sur des vaches âgées de 4 à 7 ans, ayant déjà donné un ou plusieurs veaux et pesant entre 300 et $350 \mathrm{~kg}$, non gestantes, mais à cycle non contrôlé (méthode dite aveugle).

\section{TECHNIQUE DE SYNCHRONISATION DE L'GSTRUS}

1. Traitement long: Il a été appliqué en 1971 et 1972 . Il consiste en une injection quotidienne de $5 \mathrm{mg}$ de Nilevar N.D. (Norethandrolone $=17$ éthyl - 19 nortestostérone) par voie intramusculaire, pendant 18 jours. Le $18^{\mathrm{e}}$ jour,

(*) Que nous remercions d'avoir reçu l'un d'entre nous pour se familiariser avec la technique. 
on injecte de la même façon $600 \mathrm{mg}$ de P.M.S.G. (hormone du sérum de jument gravide, jouant le rôle folliculinisant).

2. Traitement court: Les injections de Nilevar ont été limitées à 10 jours. Le premier jour, on injecte en outre $5 \mathrm{mg}$ de Valérianate d'œstradiol et le dernier jour $400 \mathrm{mg}$ de P.M.S.G.

\section{INSEMINATIONS ARTIFICIELLES}

Les inséminations ont été faites à l'aide de paillettes de sperme congelé, provenant de taureaux de race Brune des Alpes et fournis par l'intermédiaire de la SERSIA (*). Le récipient de stockage était alimenté en azote liquide depuis Tananarive où la S.O.A.M. (**) le produit.

Deux inséminations sont faites sur chacune des femelles 60 et 84 heures après l'arrêt du traitement (54 et 78 heures pour le dernier essai).

\section{RESULTATS}

Premier essai : janvier 1971 - traitement long. Insémination de 27 femelles dont 21 vaches et 6 génisses.

- Gestations : vaches - 8 sur 21.

- Gestations : génisses - 1 sur 6.

Total : 9 sur 27.

Observations: Deux gestations ont donné des naissances gémellaires. 70 p. 100 des femelles présentaient des chaleurs apparentes dans les 48 heures suivant la fin du traitement.

Deuxième essai : mai 1972 - traitement long. Insémination de 35 femelles dont 12 génisses.

- Gestations: vaches - 15 sur 23.

(*) Société d'études et de recherches scientifiques sur l'insémination artificielle.

(**) Société d'oxygène et d'acétylène de Madagascar.
- Gestations : génisses - 5 sur 12.

Total : 20 sur 35 .

Observations: Quatre gestations étaient gémellaires. L'une s'est terminée par la mort de la vache et des deux jumeaux. Sur deux autres, on a déploré la mort d'un jumeau. 80 p. 100 des femelles présentaient des chaleurs apparentes dans les 48 heures suivant la fin du traitement.

Troisième essai : février 1973 - traitement court.

Insémination de 15 femelles dont 10 génisses.

- Gestations : vaches - 4 sur 5 .

- Gestations : génisses - 5 sur 10.

Total : 9 sur 15.

Observations: Aucune gestation gémellaire. Aucun incident. 90 p. 100 des femelles ont montré des chaleurs dans les 48 heures suivant la fin du traitement.

\section{CONCLUSION}

L'insémination artificielle des femelles zébu, après synchronisation de l'œstrus, est capable de donner 60 p. 100 de vêlages. C'est donc une méthode qui peut être employée valablement.

Le traitement court, outre qu'il est plus simple, semble donner des résultats aussi satisfaisants que le traitement long. L'abaissement de la dose de P.M.S.G. diminue le risque de gestations gémellaires qui ne sont pas toujours avantageuses dans les conditions de l'élevage tropical.

On notera que, contrairement à ce qui est observé chez les taurins, les résultats sont moins bons chez les génisses que chez les vaches. Le manque de précocité physiologique du zébu est sans doute en cause. L'équinoxe d'automne (début de la saison sèche) paraît être une période favorable au succès des inséminations. Les femelles y sont en excellent état physiologique.

\section{SUMMARY}

\section{Note on artificial insemination of zebu cattle in Madagascar} after synchronisation of oestrus by Norethandrolone

Three experiments of artificial insemination of zebu cows, after synchronisation of oestrus, were described. Nilevar use gave good results (calving rate about 60 p. 100). 


\section{RESUMEN}

Nota sobre la inseminación artificial de los cebues en Madagascar despuès de sincronización del estro mediante la norethandrolone

Los autores referen tres ensayos de inseminación artificial de hembras de raza cebú después de sincronización del estro.

La utilización de la norethandrolone da buenos resultados (unos 60 p. 100 de nacimientos).

\section{BIBLIOGRAPHIE}

1. LORETTA (K.), LIANG (P.), FOSGATE (O. T.). Synchronisation of cestrus in dairy cattle with 17 alpha ethyl 19 nortestosterone (Nilevar). $J$. Anim. Sci., 1970, 31: 92-94.

2. MAULEON (P.), CHUPIN (D.). Maîtrise des cycles sexuels chez les bovins. Econ. Méd. anim., 1971, 12 : 31-44.
3. MAULEON (P.), NGUYEN HY NINH, CHUPIN (D.). Naissances gémellaires chez les bovins. Bull. tech. Inf., 1971 (257) : 205-212.

4. MAULEON (P.), PETIT (M.), CHUPIN (D.). Mâ̂trise de l'westrus et synchronisation des cycles sexuels chez les bovins. Bull. tech. Inf., 1971 (257) : 163-174. 